REVIEW ARTICLE

\title{
Superb Microvascular Imaging Assessment of Placenta Using an $18-\mathrm{MHz}$ Probe
}

\author{
Toshiyuki Hata ${ }^{1}$, Aya Koyanagi ${ }^{2}$, Riko Takayoshi $^{3}$, Takahito Miyake ${ }^{4}$, Emiko Nitta ${ }^{5}$, Kenji Kanenishi ${ }^{6}$
}

\begin{abstract}
Superb microvascular imaging (SMI) can detect low-velocity blood flow in the placenta by significantly reducing motion artifacts. Moreover, SMI using an 18- $\mathrm{MHz}$ probe generates a high-resolution image of the placental microvasculature in normal and abnormal placentas. In the normal placenta, the increased density of the placental microvasculature with advancing gestation was evident using $\mathrm{SMI}$ with an $18-\mathrm{MHz}$ probe. The placental baseline between the placenta and myometrium was also clearly identified. In the first-trimester placenta with an extremely large subchorionic hematoma, decreased vascularity in the placenta adjacent to the hematoma was clearly recognized. In the circumvallate placenta, the placental microvasculature using 18-MHz-SMI was more precisely noted compared with conventional SMI. In a case of pregnancy after a previous uterine fundal incision, a high-resolution SMI with an 18- $\mathrm{MHz}$ probe could clearly identify the very thin uterine wall. In cases of placenta accreta spectrum (PAS) during pregnancy and in the retained placenta after birth, various types of PAS were noted, and unique microvasculature was also demonstrated using SMI with an 18-MHz probe. Superb microvascular imaging with an 18-MHz probe may become a future modality to provide novel information on the antenatal evaluation of normal and abnormal placentas, and the physiologic progress of normal placental microvascular development, and precise pathologic findings of placental abnormality in clinical practice and future research. Keywords: 18-MHz probe, Circumvallate placenta, Placenta, Placenta accreta spectrum, Retained placenta, Superb microvascular imaging, Subchorionic hematoma, Uterine fundal incision.

Donald School Journal of Ultrasound in Obstetrics and Gynecology (2021): 10.5005/jp-journals-10009-1714
\end{abstract}

\section{INTRODUCTION}

The novel Doppler modality of superb microvascular imaging (SMI) (Aplio i800; Canon Medical Systems, Tokyo, Japan) uses an algorithm that minimizes motion artifacts by filtering out tissue motion (clutter), and it can be used to visualize low-velocity blood flow in small vessels of the placenta by significantly reducing motion artifacts. ${ }^{1}$ Superb microvascular imaging with Doppler Luminance is the most up-to-date color Doppler, presenting three-dimensional (3D) SMI information on a two-dimensional (2D) gray-scale image by shading that is controlled by the amplitude of the Doppler signal. ${ }^{2}$ Several SMI studies have been conducted on normal and abnormal placentas using these techniques. ${ }^{1-10}$ Recently, more meticulous assessments of the placental microvasculature were reported on employing SMI with the application of an 18-MHz probe (PLI1205BX, Canon Medical Systems, Tokyo, Japan). ${ }^{11-13}$

Here, the most up-to-date state-of-the-art SMI of normal and abnormal placental microvasculatures using an $18-\mathrm{MHz}$ probe is presented. Present and future applications of this novel technique to assess normal and abnormal placentas in clinical practice are also considered.

\section{Normal Placenta}

Fifteen anterior implanted placentas at $16-40$ weeks of gestation were evaluated with SMI with an 18-MHz probe. Smart 3D was used to reconstruct the spatial placental microvasculature. ${ }^{4,11}$

\section{Placental Microvasculature}

The tertiary stem villous vessels could be seen around 16 weeks (Fig. 1), and they showed increasing complexity after 16 weeks to term (Figs 1 to 5). Spiral arteries could be seen discharging blood into the intervillous space, and the terminal ends of these vessels suggested successful trophoblastic invasion (Figs 1, 2, 4,

\footnotetext{
1,4 Department of Obstetrics and Gynecology, Miyake Clinic, Okayama, Japan; Department of Perinatology and Gynecology, Kagawa University Graduate School of Medicine, Kagawa, Japan

${ }^{2,3}$ Department of Obstetrics and Gynecology, Miyake Clinic, Okayama, Japan

${ }^{5,6}$ Department of Perinatology and Gynecology, Kagawa University Graduate School of Medicine, Kagawa, Japan

Corresponding Author: Toshiyuki Hata, Department of Obstetrics and Gynecology, Miyake Clinic, Okayama, Japan; Department of Perinatology and Gynecology, Kagawa University Graduate School of Medicine, Kagawa, Japan, Phone: +81-(0)87-891-2174, e-mail: toshi28@med.kagawa-u.ac.jp

How to cite this article: Hata T, Koyanagi A, Takayoshi R, et al. Superb Microvascular Imaging Assessment of Placenta Using an 18-MHz Probe. Donald School J Ultrasound Obstet Gynecol 2021;15(3):312-322.

Source of support: Nil

Conflict of interest: None
}

and 5). The increased density of the placental microvasculature was evident using SMI with an 18-MHz probe compared with that with conventional SMI (Figs 6 and 7).

\section{Placental Baseline}

The placental baseline between placenta and myometrium could be clearly identified at $16-40$ weeks of gestation (Figs 8 to 12). The arcuate artery and decidual vessels were also evident using SMI with an $18-\mathrm{MHz}$ probe.

\section{Subchorionic Hematoma}

In a case with vaginal bleeding at 12 weeks and 5 days of gestation, 2D sonography showed an extremely large

() Jaypee Brothers Medical Publishers. 2021 Open Access This article is distributed under the terms of the Creative Commons Attribution 4.0 International License (https://creativecommons.org/licenses/by-nc/4.0/), which permits unrestricted use, distribution, and non-commercial reproduction in any medium, provided you give appropriate credit to the original author(s) and the source, provide a link to the Creative Commons license, and indicate if changes were made. The Creative Commons Public Domain Dedication waiver (http://creativecommons.org/publicdomain/zero/1.0/) applies to the data made available in this article, unless otherwise stated. 


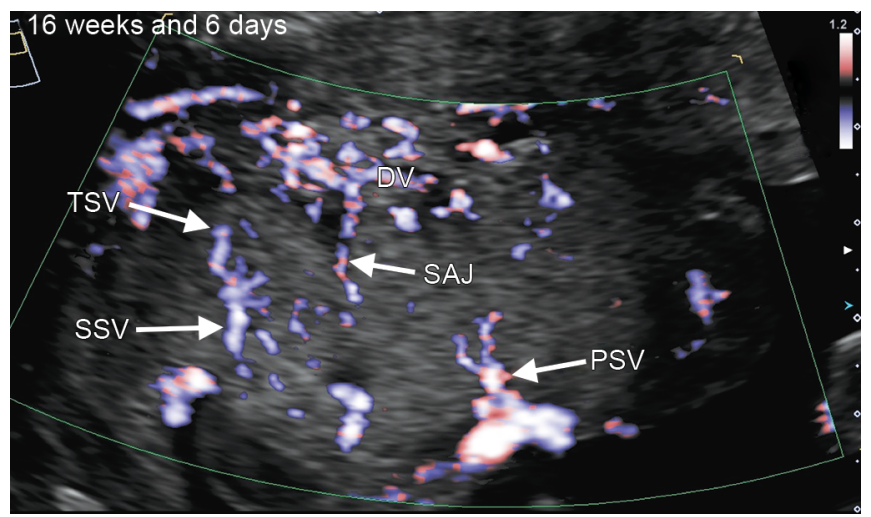

Fig. 1: Normal placenta at 16 weeks and 6 days of gestation on color-coded superb microvascular imaging (SMI) with an 18-MHz linear probe. DV, decidual vessel; PSV, primary stem villous vessels; SAJ, spiral artery jet flow; SSV, secondary stem villous vessels; TSV, tertiary stem villous vessel
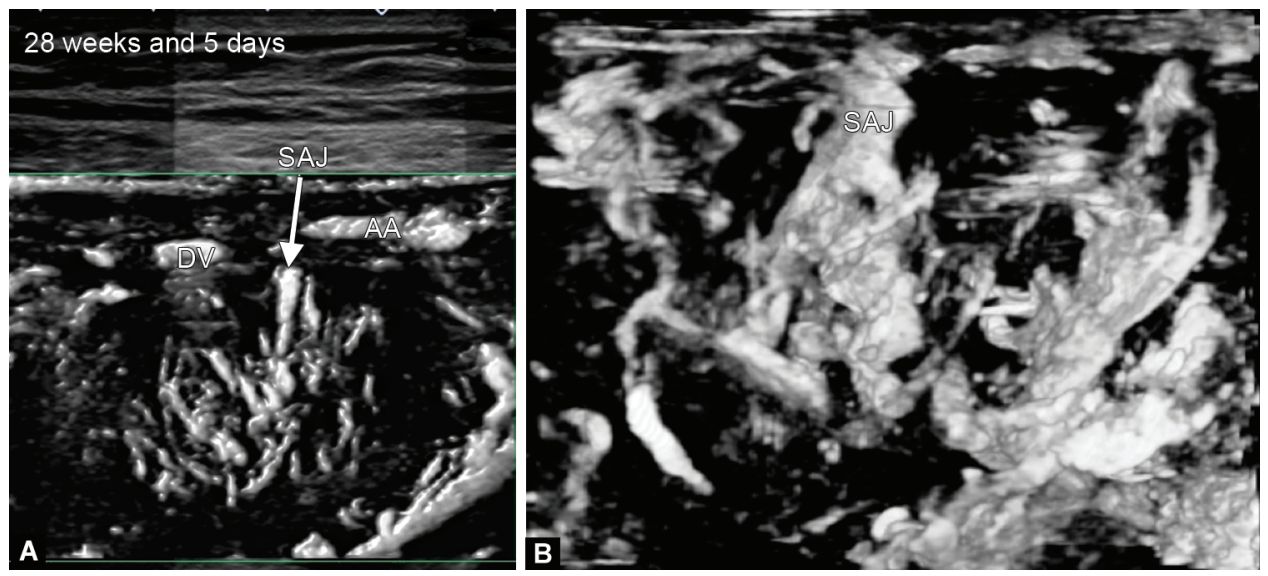

Figs $2 \mathrm{~A}$ and B: Normal placenta at 28 weeks and 5 days of gestation on superb microvascular imaging (SMI) with an 18-MHz linear probe. (A) Twodimensional SMI image with Doppler Luminance; (B) Three-dimensional SMI image. AA, arcuate artery; DV, decidual vessel; SAJ, spiral artery jet flow
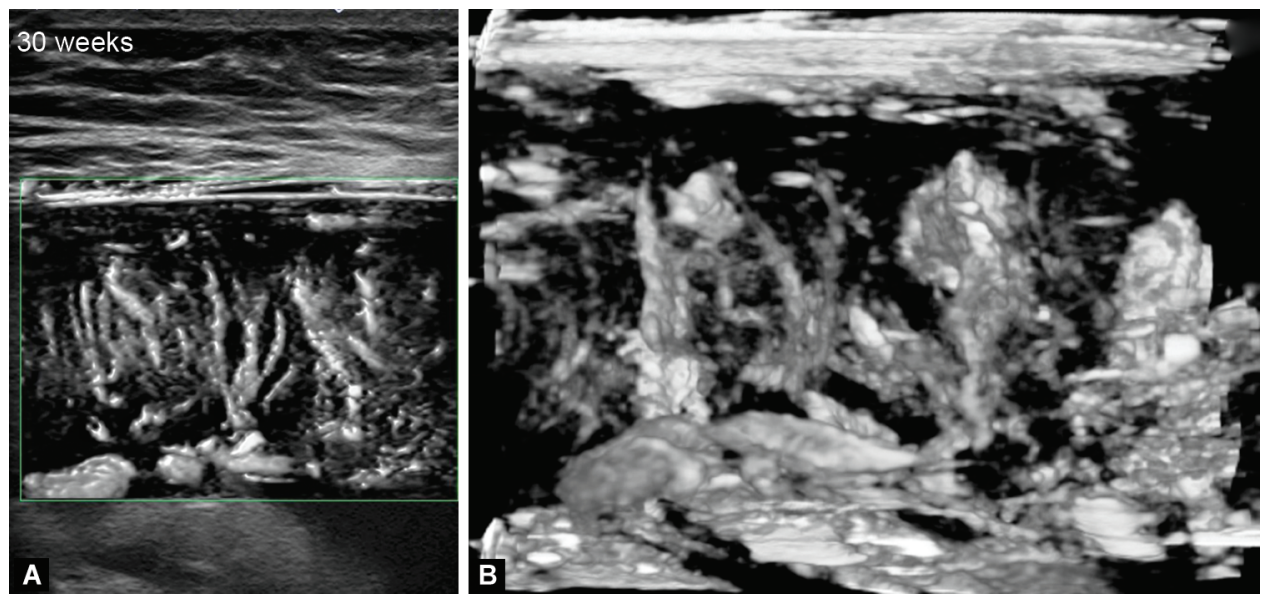

Figs $3 \mathrm{~A}$ and B: Normal placenta at 30 weeks of gestation on superb microvascular imaging (SMI) with an 18-MHz linear probe. (A) Two-dimensional SMI image with Doppler Luminance; (B) Three-dimensional SMI image

subchorionic hematoma (Fig. 13). Conventional SMI and SD $\mathrm{SMI}$ revealed an avascular area in the placenta adjacent to the hematoma (Figs 14 and 15). Slightly increased echogenicity was noted in the placenta adjacent to the hematoma using $18-\mathrm{MHz}$ 2D sonography, and decreased vascularity was clearly recognized in the same area using SMI with an 18-MHz probe (Fig. 16). Smart $3 \mathrm{D}$ using an 18-MHz probe demonstrated a few main stem villous vessels in the avascular area of the placenta, whereas tertiary stem villous vessels were identified in the normal-echogenicity placenta (Fig. 17). 

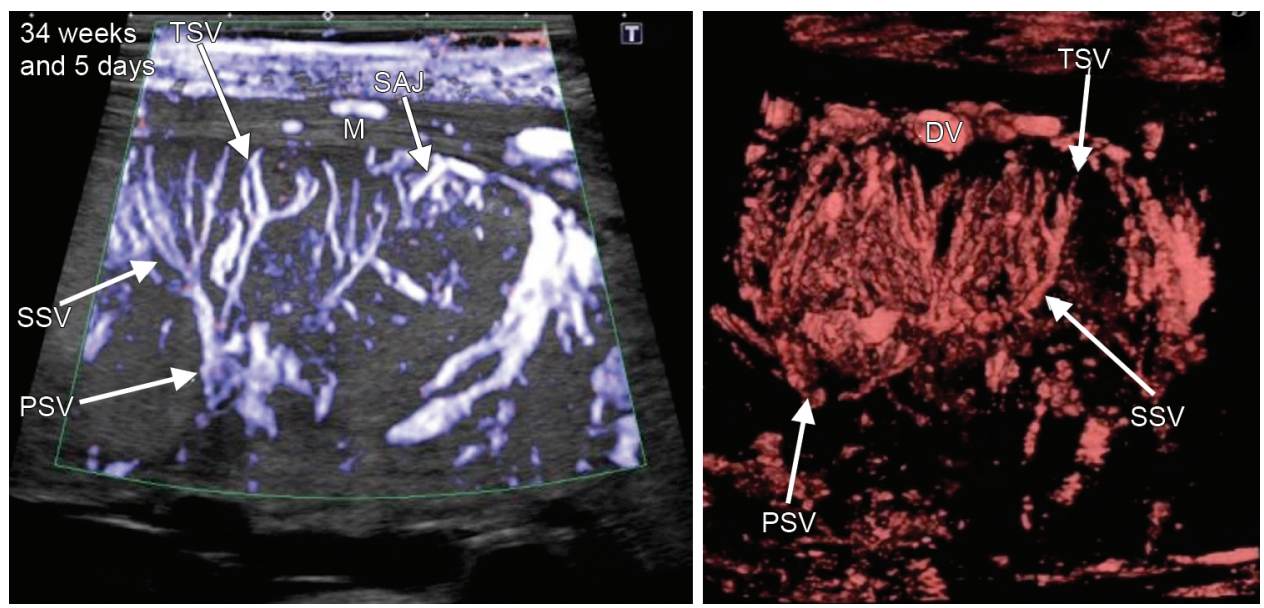

Figs 4A and B: Normal placenta at 34 weeks and 5 days of gestation on superb microvascular imaging (SMI) with an 18-MHz linear probe. (A) Twodimensional color-coded SMI image; (B) Three-dimensional SMI image. DV, decidual vessel; M, myometrium; PSV, primary stem villous vessels; SAJ, spiral artery jet flow; SSV, secondary stem villous vessels; TSV, tertiary stem villous vessel. Courtesy: Reprinted with permission from Jaypee Brothers Medical Publishers (P) Ltd. ${ }^{11}$
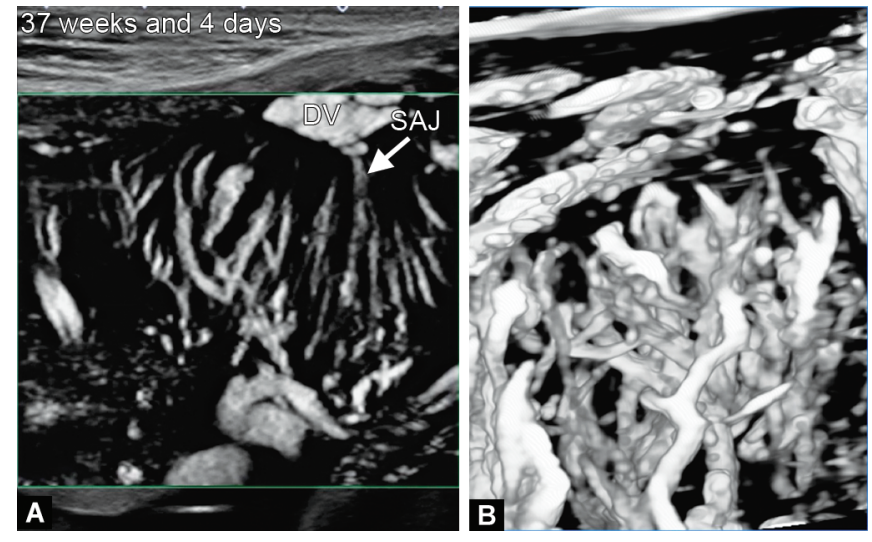

Figs $5 \mathrm{~A}$ and $\mathrm{B}$ : Normal placenta at 37 weeks and 4 days of gestation on superb microvascular imaging (SMI) with an 18- $\mathrm{MHz}$ linear probe. (A) Two-dimensional SMI image; (B) Three-dimensional SMI image. DV, decidual vessel; SAJ, spiral artery jet flow
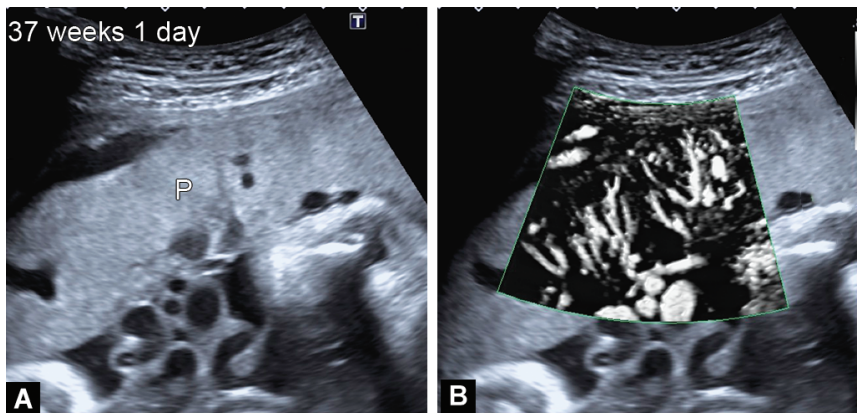

Figs $6 \mathrm{~A}$ and B: Normal placenta at 37 weeks and 1 day of gestation on superb microvascular imaging (SMI). (A) Two-dimensional sonographic image; (B) Conventional SMI image with Doppler luminance. P, placenta
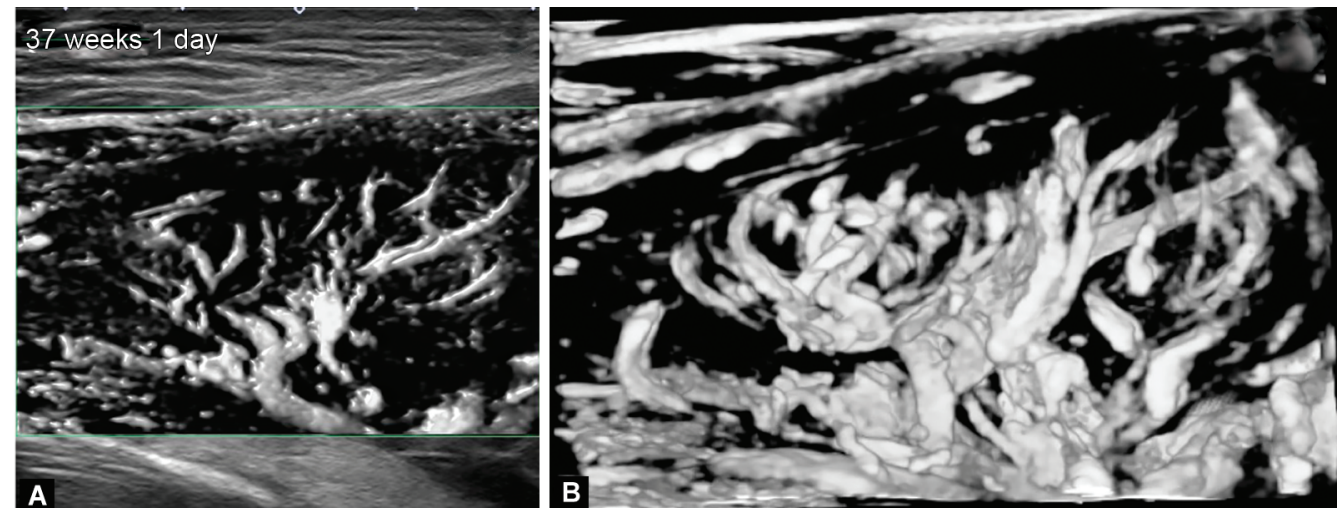

Figs 7A and B: Normal placenta at 37 weeks and 1 day of gestation on superb microvascular imaging (SMI) with an 18-MHz linear probe. (A) Twodimensional SMI image with Doppler Luminance; (B) Three-dimensional SMI image 


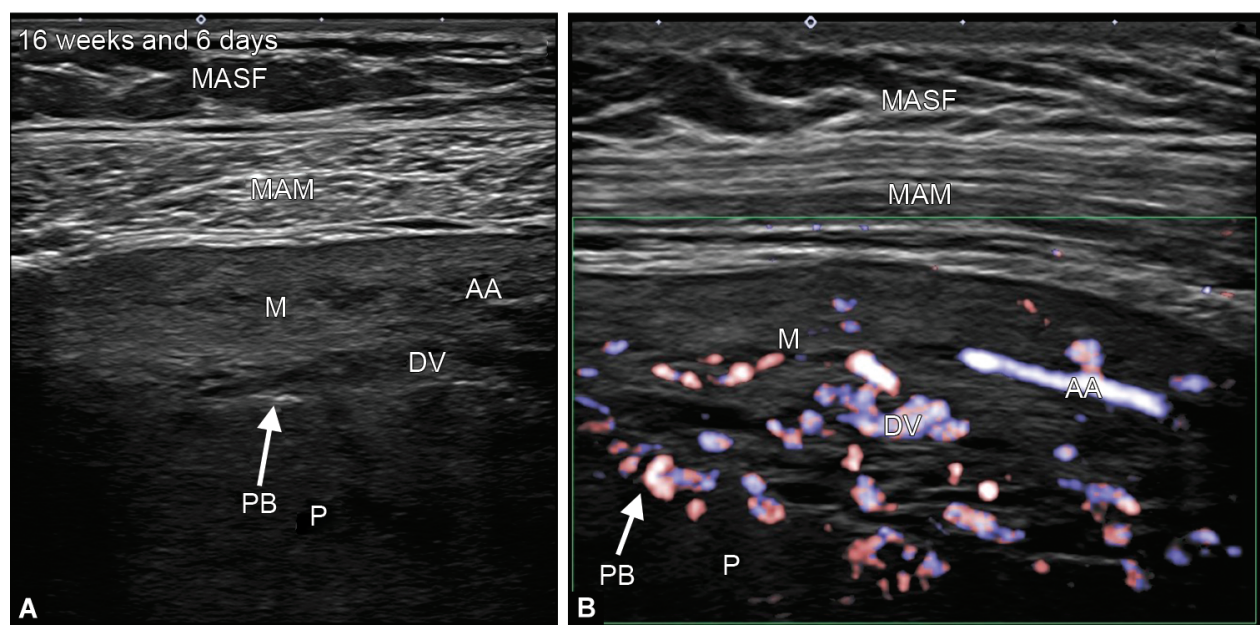

Figs $8 \mathrm{~A}$ and B: Normal placenta at 16 weeks and 6 days of gestation on superb microvascular imaging (SMI) with an 18-MHz linear probe. SMI clearly shows a placental baseline (PB) with decidual vessels (DV) between the placenta and myometrium. The uterine wall (M) is thick, and arcuate arteries (AA) in the uterine wall are also noted. (A) High-resolution two-dimensional sonographic image; (B) High-resolution color-coded SMI image. MAM, maternal abdominal muscle; MASF, maternal abdominal subcutaneous fat; $P$, placenta
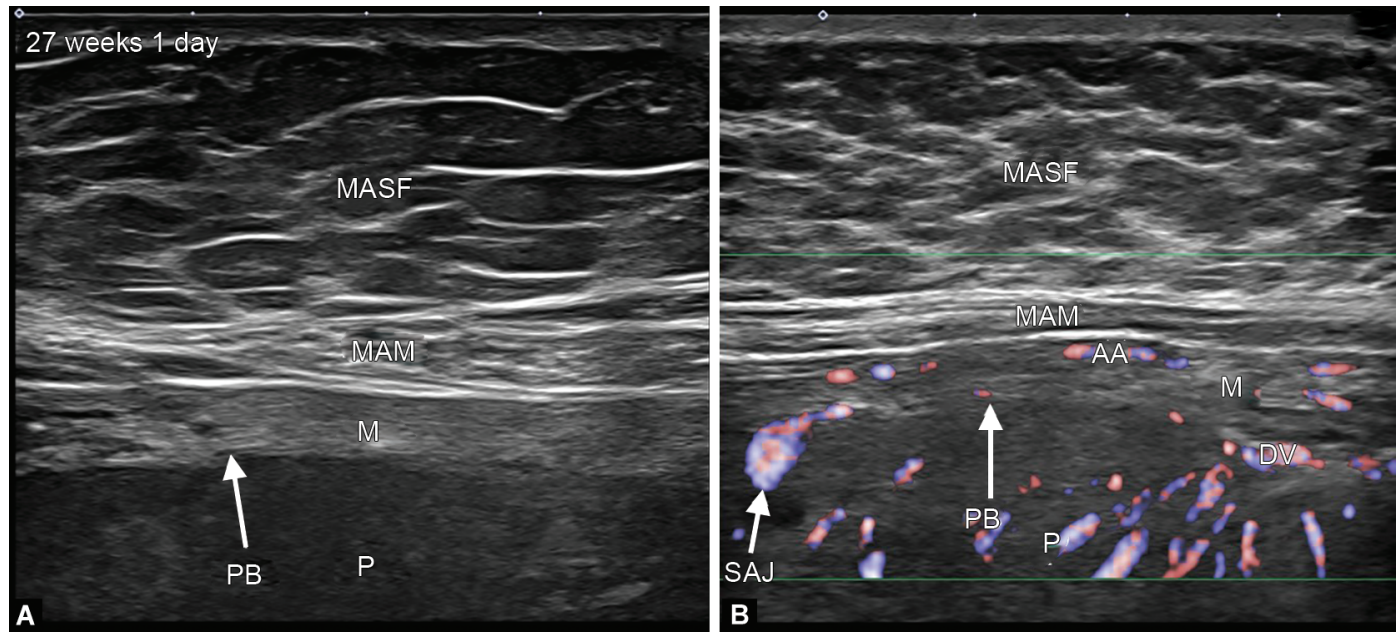

Figs 9A and B: Normal placenta at 27 weeks and 1 day of gestation on superb microvascular imaging (SMI) with an 18-MHz linear probe. SMI clearly shows a placental baseline (PB) with/without decidual vessels (DV) between the placenta and myometrium. The uterine wall (M) is thick, and arcuate arteries (AA) in the uterine wall are also noted. (A) High-resolution two-dimensional sonographic image; (B) High-resolution colorcoded SMI image. MAM, maternal abdominal muscle; MASF, maternal abdominal subcutaneous fat; $P$, placenta
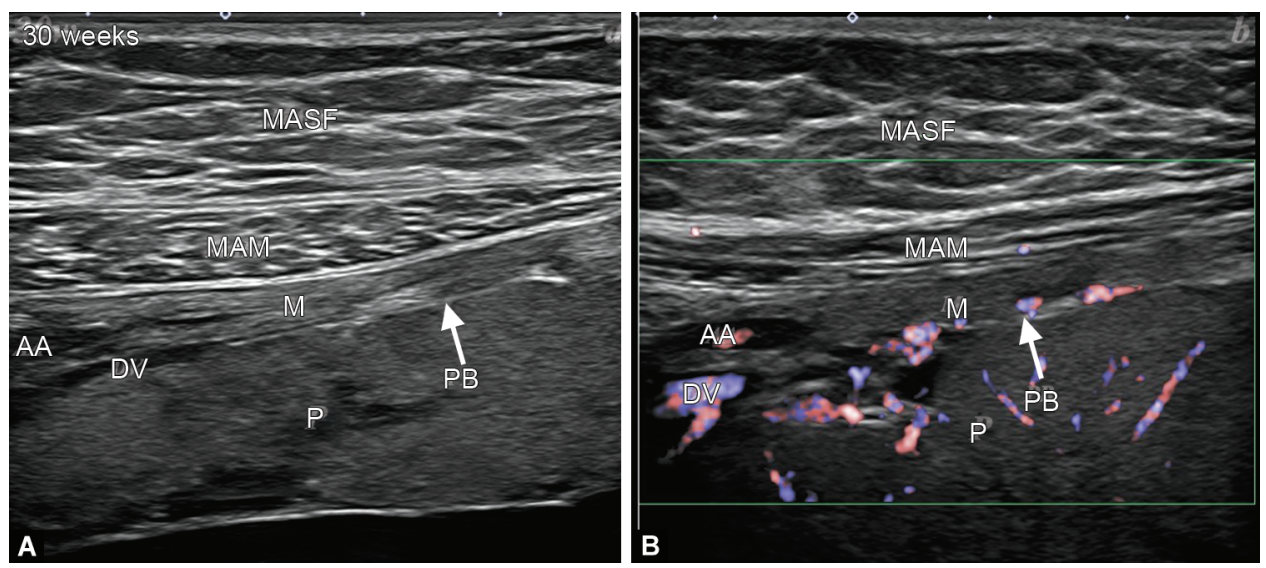

Figs 10A and B: Normal placenta at 30 weeks of gestation on superb microvascular imaging (SMI) with an 18-MHz linear probe. SMI clearly shows a sharp placental baseline (PB) with decidual vessels (DV) between the placenta and myometrium. The uterine wall (M) is thick, and arcuate arteries (AA) in the uterine wall are also noted. (A) High-resolution two-dimensional sonographic image; (B) High-resolution color-coded SMI image. MAM, maternal abdominal muscle; MASF, maternal abdominal subcutaneous fat; P, placenta. Courtesy: Reprinted with permission from Jaypee Brothers Medical Publishers (P) Ltd. ${ }^{11}$ 


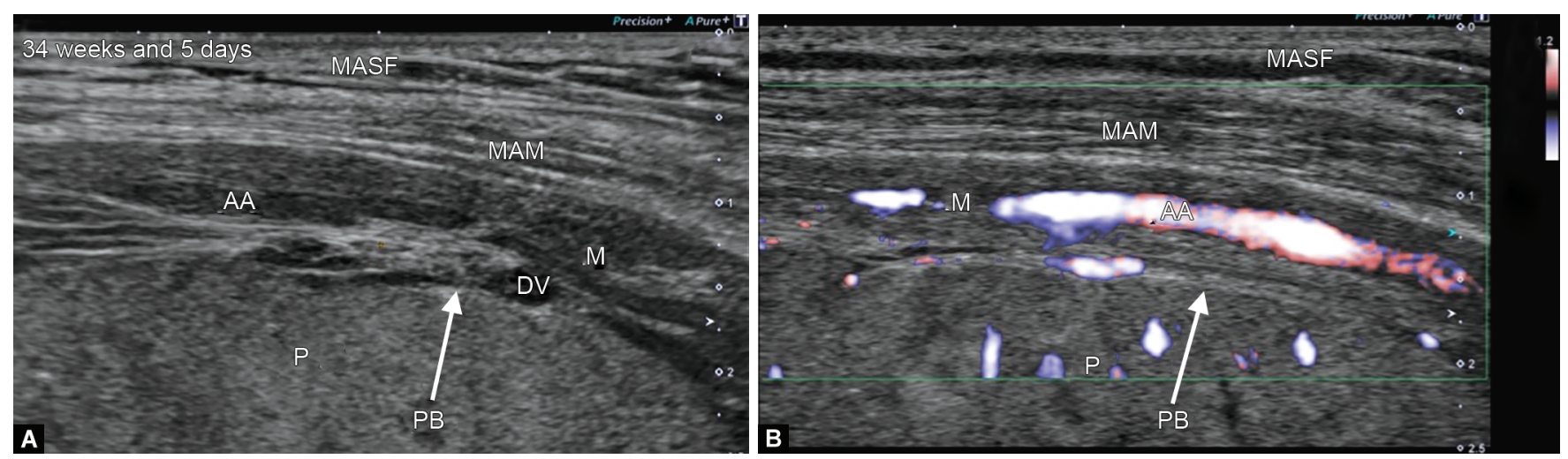

Figs $11 \mathrm{~A}$ and B: Normal placenta at 34 weeks and 5 days of gestation on superb microvascular imaging (SMI) with an 18-MHz linear probe. SMI clearly shows a sharp placental baseline (PB) with/without decidual vessels (DV) between the placenta and myometrium. The uterine wall (M) is thick, and arcuate arteries (AA) in the uterine wall are also noted. (A) High-resolution two-dimensional sonographic image; (B) High-resolution color-coded SMI image. MAM, maternal abdominal muscle; MASF, maternal abdominal subcutaneous fat; P, placenta
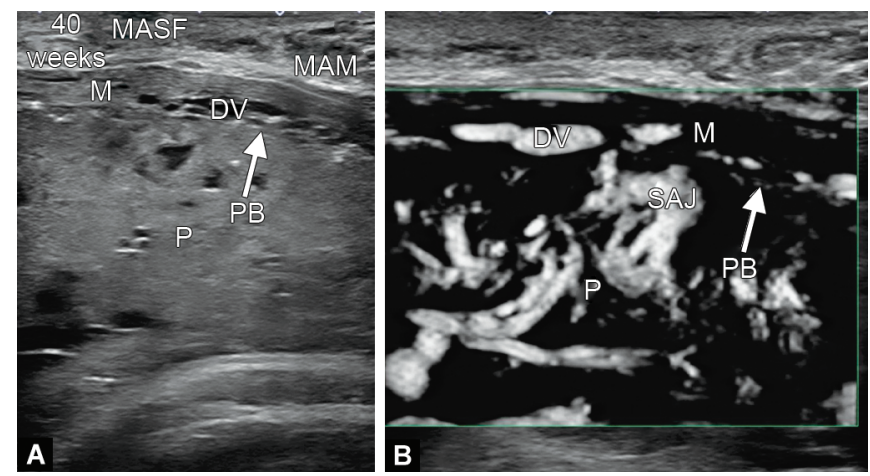

Figs $12 \mathrm{~A}$ and B: Normal placenta at 40 weeks of gestation on superb microvascular imaging (SMI) with an 18- $\mathrm{MHz}$ linear probe. SMI clearly shows a placental baseline (PB) with decidual vessels (DV) between the placenta and myometrium. The uterine wall $(M)$ is thick. $(A)$ Highresolution two-dimensional sonographic image; (B) High-resolution monochrome SMI image. MAM, maternal abdominal muscle; MASF, maternal abdominal subcutaneous fat; P, placenta

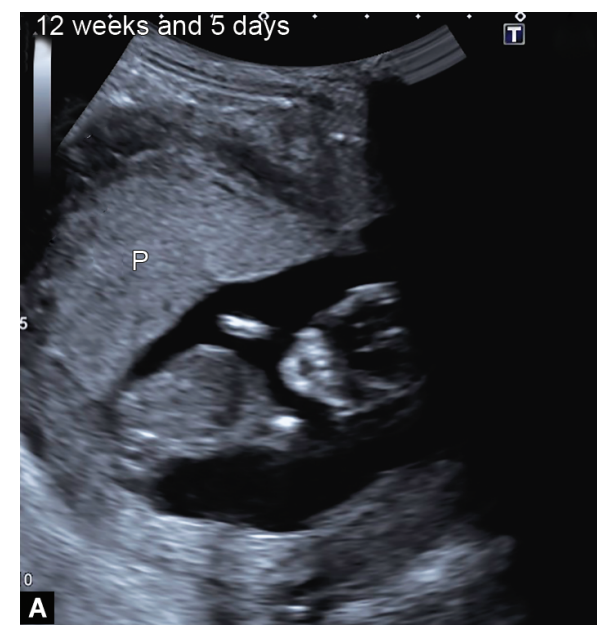

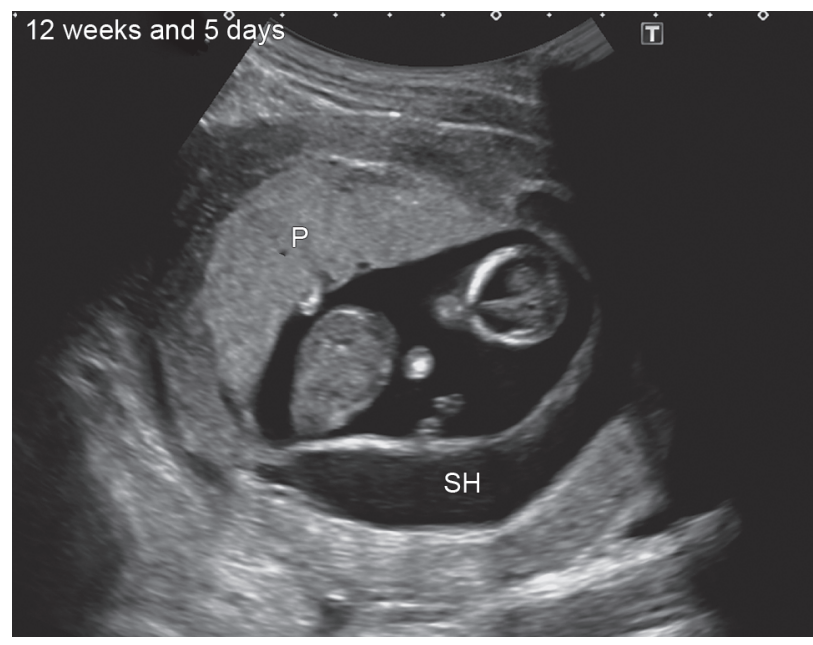

Fig. 13: Large subchorionic hematoma (SH) adjacent to the placenta (P) using conventional two-dimensional sonography at 12 weeks and 5 days of gestation

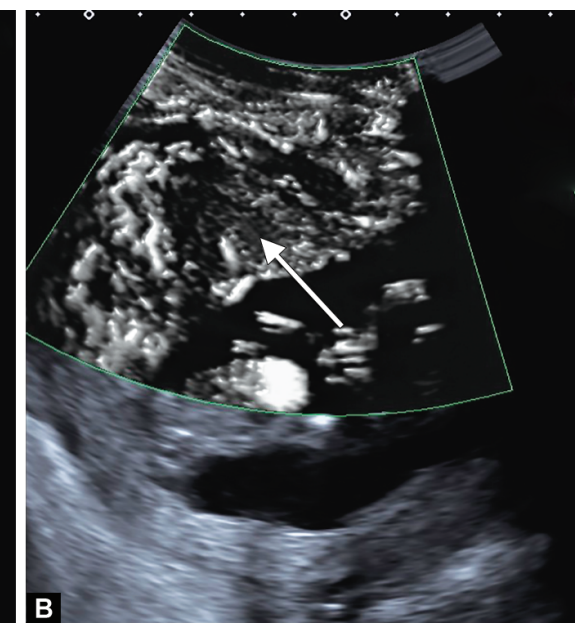

Figs 14A and B: Large subchorionic hematoma adjacent to the placenta $(\mathrm{P})$ at 12 weeks and 5 days of gestation. Conventional superb microvascular imaging (SMI) reveals an avascular area (arrow) in the placenta adjacent to the hematoma. (A) Two-dimensional sonographic image; (B) Conventional SMI image with Doppler Luminance 


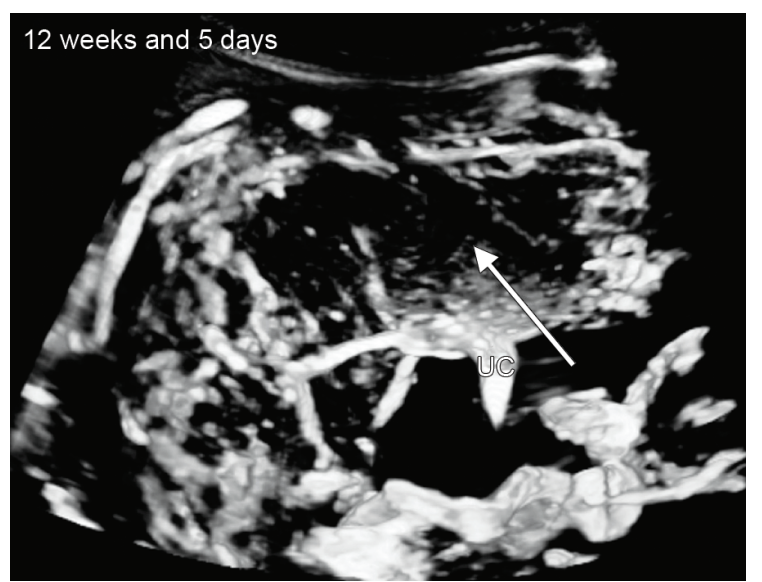

Fig. 15:Three-dimensional (3D) reconstruction of placental vasculature in the case of a large subchorionic hematoma using conventional 3D superb microvascular imaging (SMI) at 12 weeks and 5 days of gestation. An avascular area (arrow) in the placenta adjacent to the hematoma can be clearly noted. UC, umbilical cord

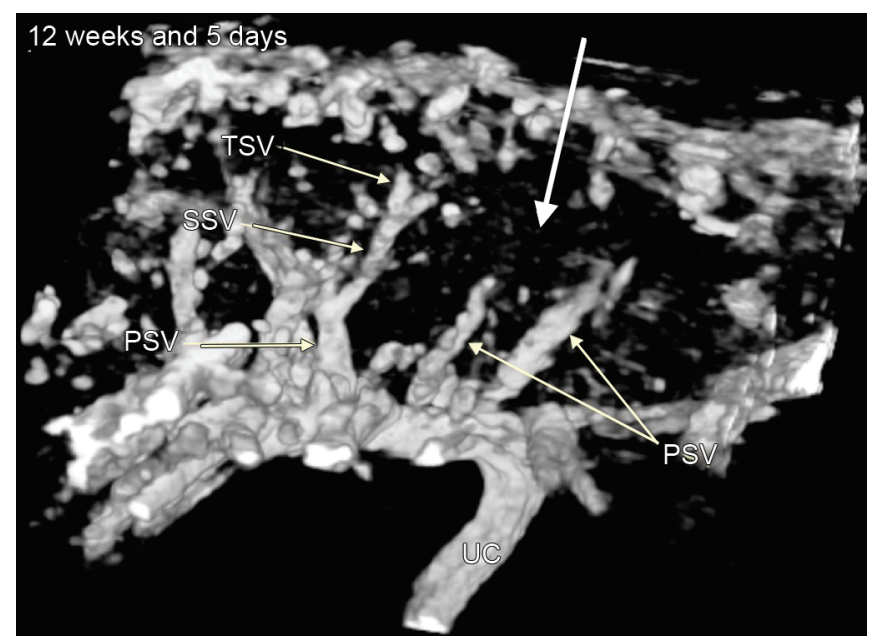

Fig. 17: Three-dimensional (3D) reconstruction of placental microvasculature in the case of a large subchorionic hematoma using 3D superb microvascular imaging (SMI) with an $18-\mathrm{MHz}$ probe at 12 weeks and 5 days of gestation. Smart 3D using an 18-MHz probe demonstrates a few primary stem villous vessels (PVS) in the avascular area of the placenta (large arrow), whereas tertiary stem villous vessels (TVS) were identified in the normal-echogenicity placenta. SSV, secondary stem villous vessel; UC, umbilical cord

\section{Circumvallate Placenta}

A placenta with increased thickness and rolled up edges protruding into the uterine cavity was noted on a 2D sonographic image at a gestational age of 28 weeks and 5 days, ${ }^{2}$ and conventional SMI could visualize moderate intra-placental vessels (Fig. 18). Spatial relationships of intra-placental blood vessels were clearly noted using conventional smart 3D (Fig. 19). The placental microvasculature was clearer using $18-\mathrm{MHz}$ SMI than conventional SMI (Fig. 20). The diagnosis could be confirmed with a gross specimen of the placenta after birth (Fig. 21).
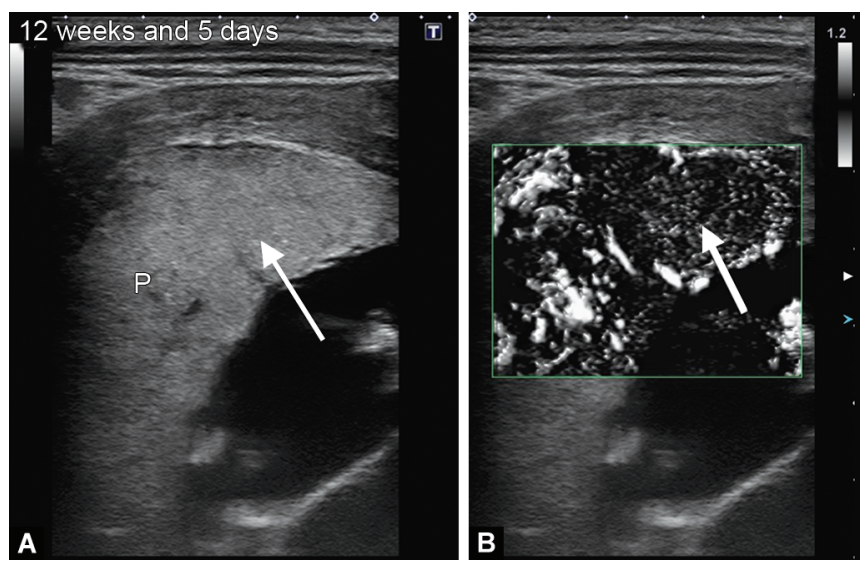

Figs 16A and B: Large subchorionic hematoma adjacent to the placenta ( $P$ ) at 12 weeks and 5 days of gestation. High-resolution 2D sonography shows slightly increased echogenicity (small arrow) in an avascular area (large arrow) of the placenta adjacent to the hematoma. (A) High-resolution two-dimensional sonographic image; (B) High-resolution SMI image
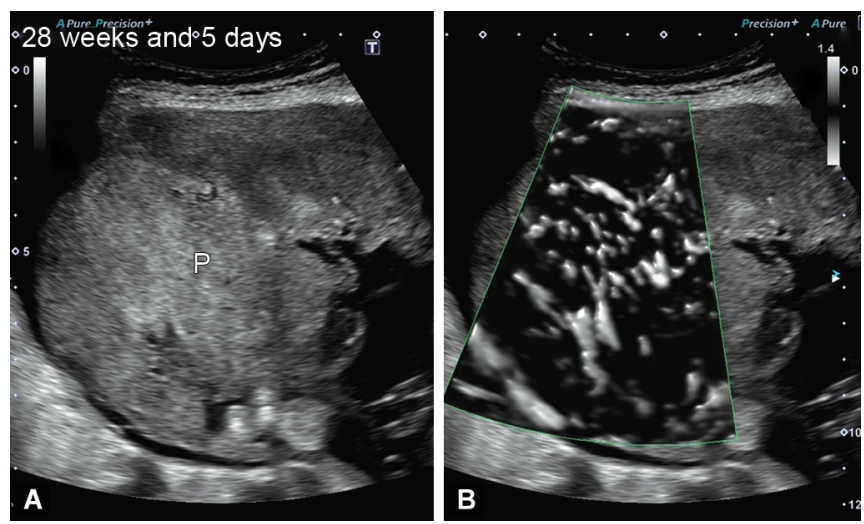

Figs $18 \mathrm{~A}$ and $\mathrm{B}$ : Circumvallate placenta $(\mathrm{P})$ depicted by conventional superb microvascular imaging (SMI) at 28 weeks and 5 days of gestation. (A) Two-dimensional sonographic image; (B) Conventional SMI image with Doppler luminance. Courtesy: Reprinted with permission from Jaypee Brothers Medical Publishers (P) Ltd. ${ }^{2}$
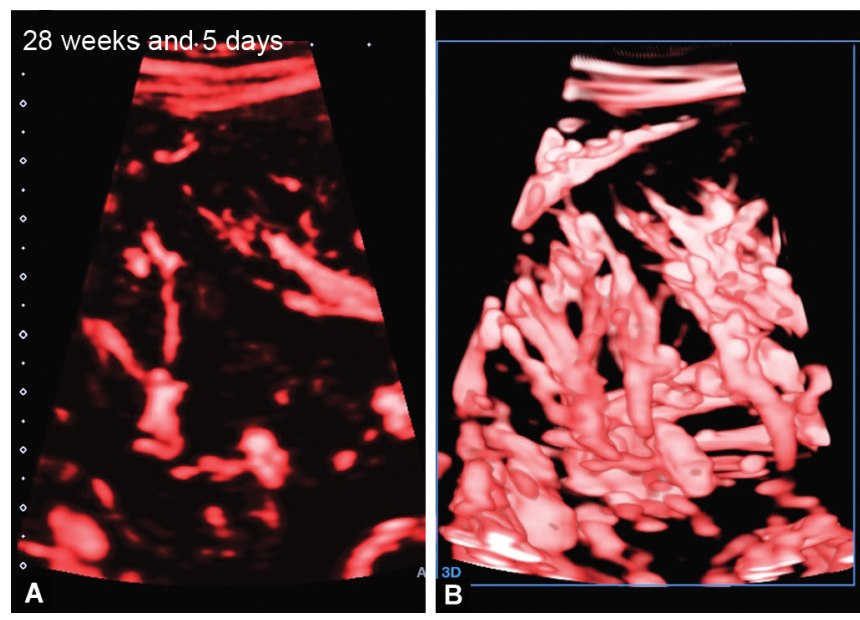

Figs 19A and B: Three-dimensional (3D) reconstruction of placental vasculature in the case of a circumvallate placenta using conventional $3 \mathrm{D}$ superb microvascular imaging (SMI) at 28 weeks and 5 days of gestation. (A) Conventional SMI image; (B) Conventional 3D SMI image. Courtesy: Reprinted with permission from Jaypee Brothers Medical Publishers (P) Ltd. ${ }^{2}$ 

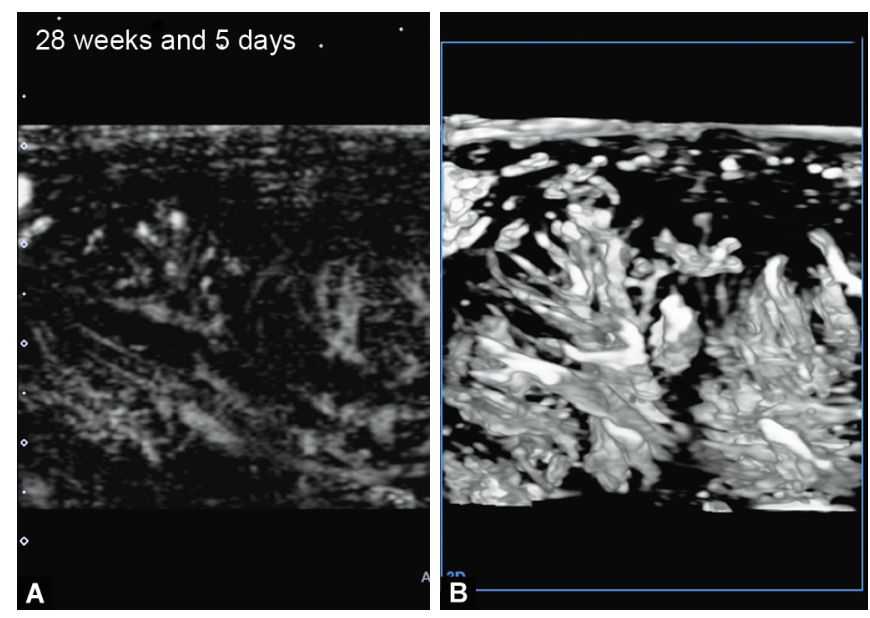

Figs $20 \mathrm{~A}$ and $\mathrm{B}$ : Three-dimensional (3D) reconstruction of placental microvasculature in the case of a circumvallate placenta using 3D superb microvascular imaging (SMI) with an 18-MHz probe at 28 weeks and 5 days of gestation. (A) High-resolution SMI image; (B) High-resolution 3D SMI image. Courtesy: Reprinted with permission from Jaypee Brothers Medical Publishers (P) Ltd. ${ }^{2}$

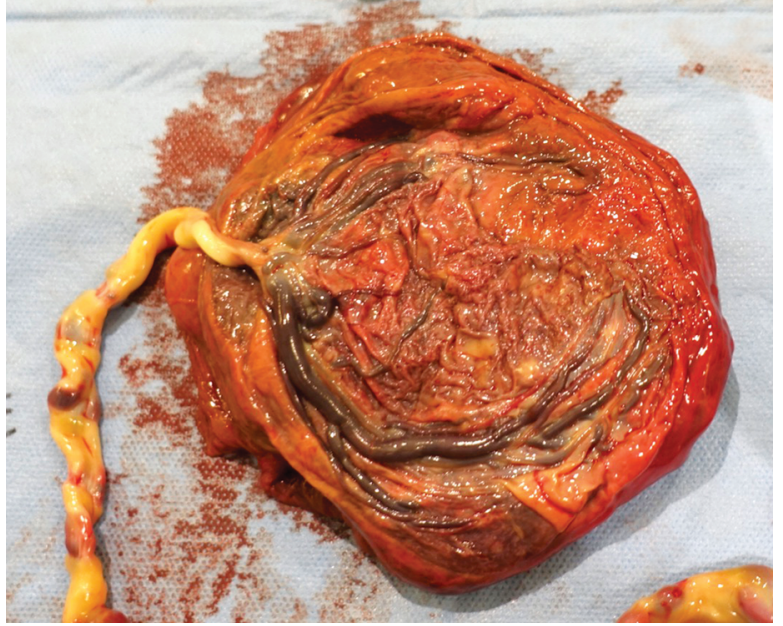

Fig. 21: Gross specimen of a circumvallate placenta. Courtesy: Reprinted with permission from Jaypee Brothers Medical Publishers (P) Ltd. $^{2}$
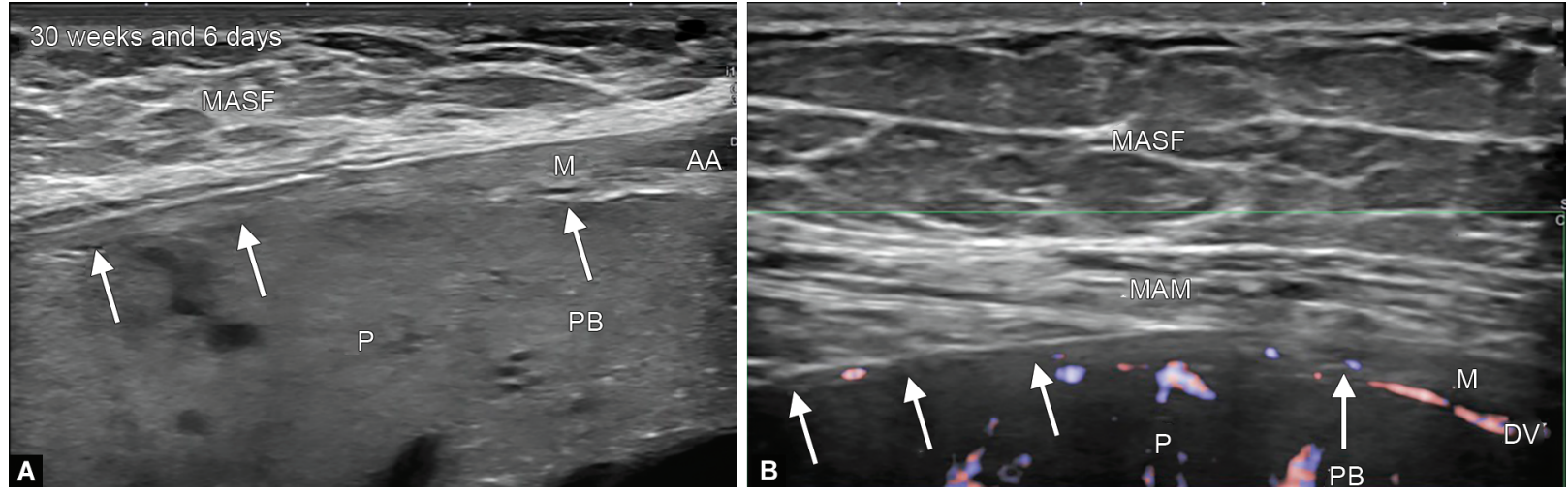

Figs 22A and B: Pregnancy after previous uterine fundal incision using superb microvascular imaging (SMI) with an 18-MHz probe at 30 weeks and 6 days of gestation. A very thin uterine wall (arrows) is evident. The placental baseline (PB) is clearly identified. (A) High-resolution two-dimensional sonographic image; (B) High-resolution SMI image. AA, arcuate artery; DV, decidual vessel; M, myometrium; MAM, maternal abdominal muscle; MASF, maternal abdominal subcutaneous fat; $P$, placenta. Courtesy: Reprinted with permission from Jaypee Brothers Medical Publishers (P) Ltd. ${ }^{11}$

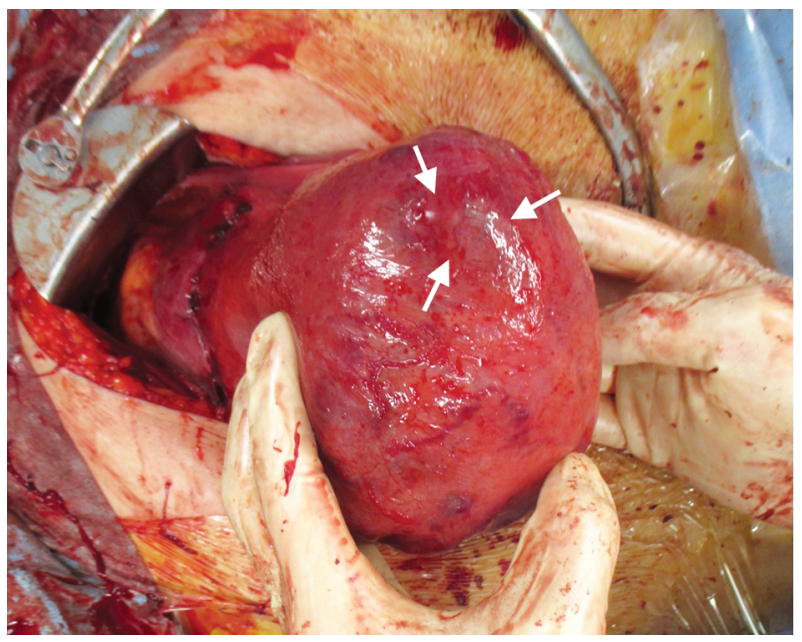

Fig. 23: Macroscopic findings of the uterus during the operation. A membranous uterine wall at the fundal lesion (arrows) is evident. Courtesy: Reprinted with permission from Jaypee Brothers Medical Publishers (P) Ltd. ${ }^{11}$

\section{Previous Uterine Fundal Incision}

In a patient achieving pregnancy after a previous uterine fundal incision, at 30 weeks and 6 days of gestation, ${ }^{11}$ conventional 2D sonography failed to identify a uterine wall. Conversely, the modality of high-resolution SMI with an 18-MHz probe clearly depicted a very thin wall (Fig. 22). The placental baseline could be clearly presented. Also, there was no abnormal blood flow. During surgery, placental removal was possible without any adhesion. The membranous uterine wall at the fundal lesion could be clearly identified (Fig. 23).

\section{Placenta Accreta Spectrum}

Regarding the first case of placenta accreta spectrum (PAS) at 37 weeks and 4 days of gestation, placental baseline disruption and lack of a uterine wall were clearly noted using SMI with an 18-MHz probe (Fig. 24). Placenta accreta spectrum was identified intraoperatively (Fig. 25).

In the second case of PAS at a gestational age of 31 weeks and 4 days, ${ }^{2}$ the lower anterior segment of the uterus showed significant dilatation of decidual vessels (Fig. 26). 

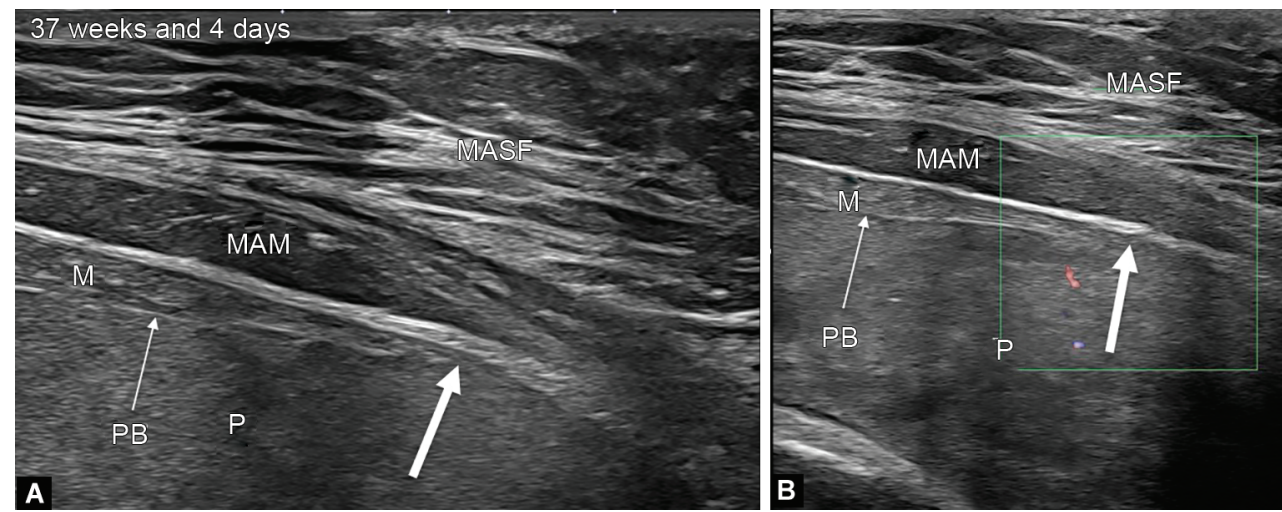

Figs 24A and B: Placenta accreta spectrum using superb microvascular imaging (SMI) with an 18-MHz probe at 37 weeks and 4 days of gestation. Disruption (large arrow) of the placental baseline (PB) and uterine wall absence can be clearly identified using this technique. (A) High-resolution two-dimensional sonographic image; (B) High-resolution SMI image. M, myometrium; MAM, maternal abdominal muscle; MASF, maternal abdominal subcutaneous fat; $P$, placenta

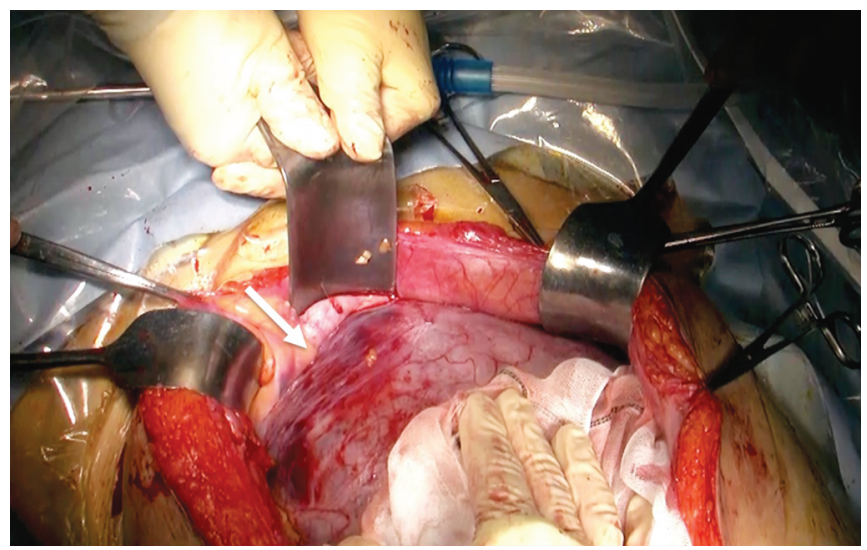

Fig. 25: Macroscopic findings of the uterus during the operation. Placenta accreta spectrum (arrow) is evident
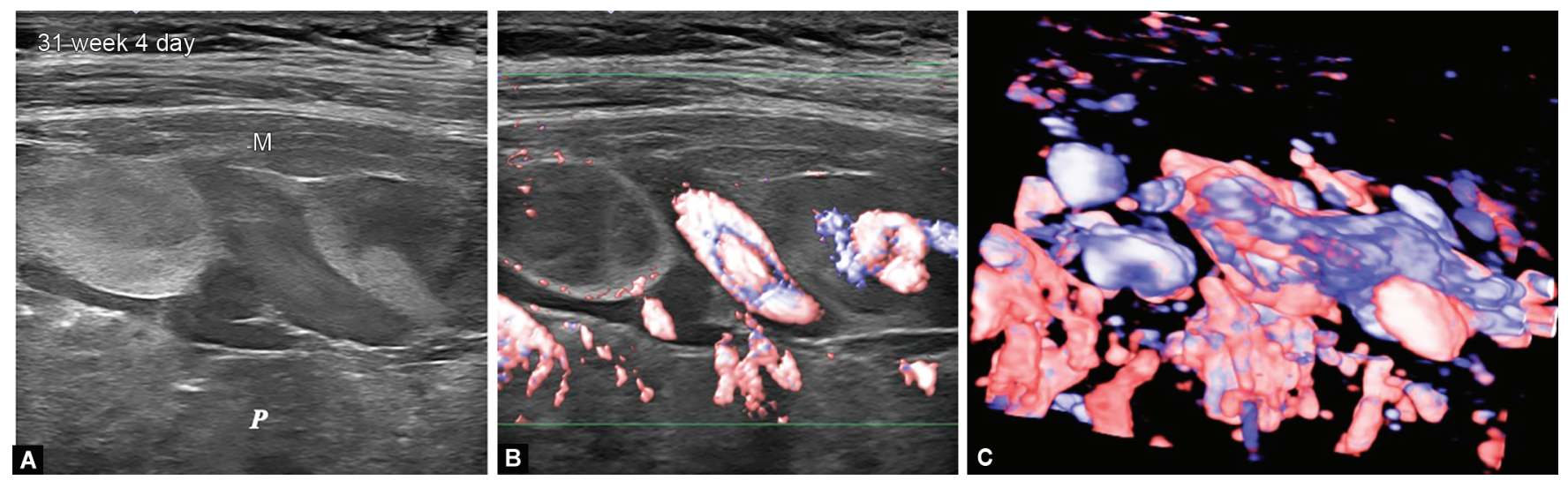

Figs 26A to C: Placenta accreta spectrum depicted by superb microvascular imaging (SMI) with an 18-MHz probe at 31 weeks and 4 days of gestation. (A) High-resolution two-dimensional sonographic image; (B) High-resolution color-coded SMI image with Doppler luminance; (C) High-resolution three-dimensional SMI image. M, myometrium; P, placenta. Courtesy: Reprinted with permission from Jaypee Brothers Medical Publishers (P) Ltd. ${ }^{2}$ 


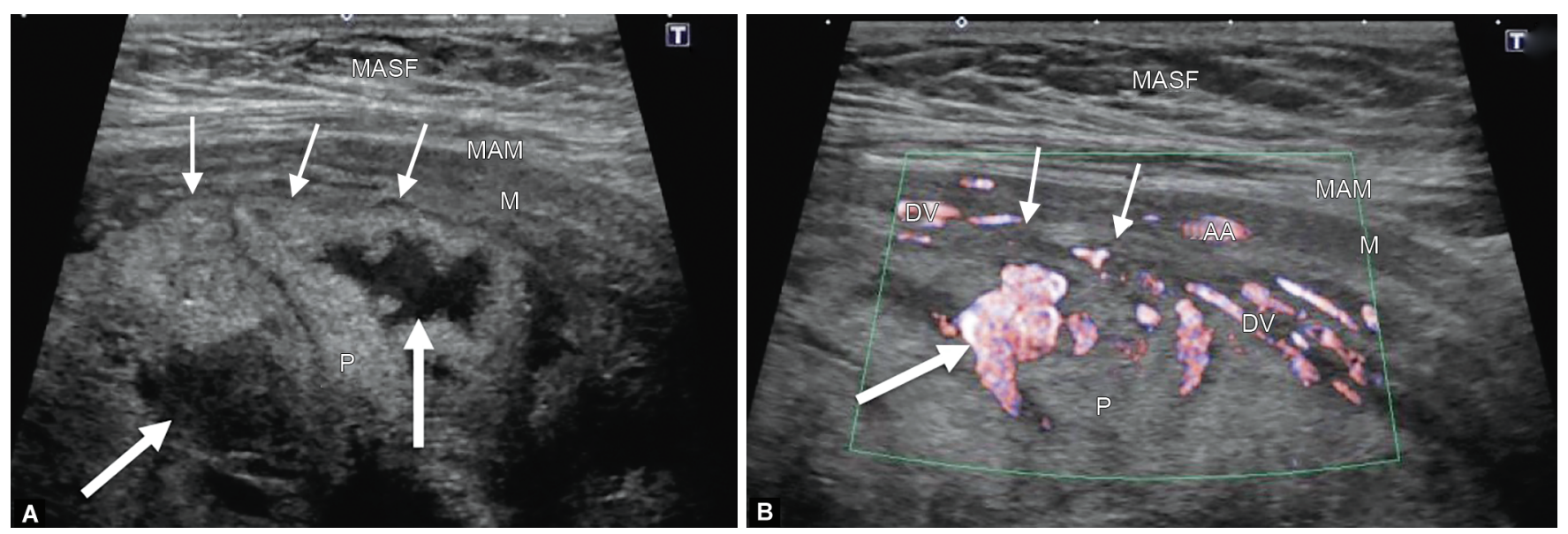

Figs 27A and B: Retained placenta with placenta accreta spectrum. (A) High-resolution two-dimensional sonography with an 18-MHz linear probe clearly demonstrates irregular minimal invasion of the retained placenta into the anterior myometrium (small arrows), and a thin uterine wall is noted. Large echo-free spaces are evident (large arrows); (B) Superb microvascular imaging (SMI) with an 18-MHz linear probe reveals a minimally invasive placenta in the anterior myometrium (small arrows), and the disruption of decidual vessels (DV). Abnormal placental flow is also noted (large arrow). M, myometrium; MAM, maternal abdominal muscle; MASF, maternal abdominal subcutaneous fat, P, placenta. Courtesy: Reprinted with permission from Jaypee Brothers Medical Publishers (P) Ltd. $^{12}$
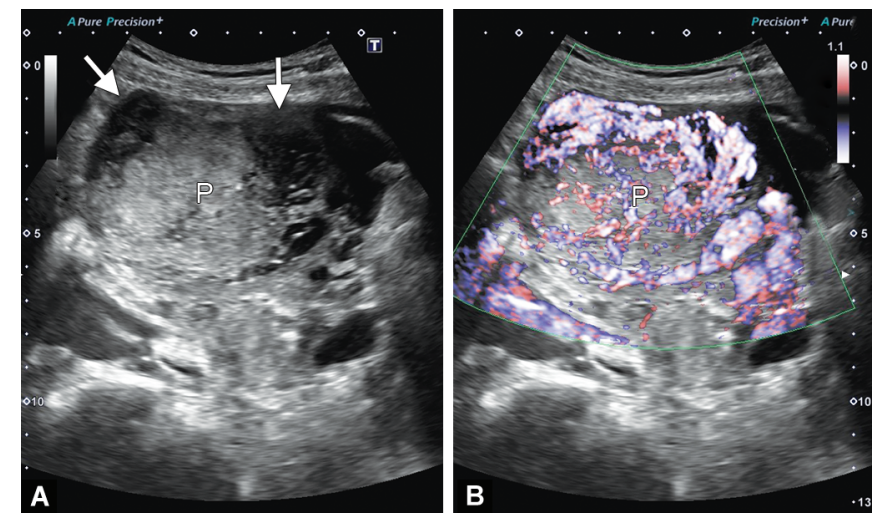

Figs $28 \mathrm{~A}$ and B: Retained placenta with placenta accreta spectrum. (A) Two-dimensional sonography shows broad anechoic lesions in the uterus (arrows); (B) Conventional color-coded superb microvascular imaging (SMI) reveals abundant blood flow in the placental bed adjacent to the uterine wall. P, placenta. Courtesy: Reprinted with permission from Jaypee Brothers Medical Publishers (P) Ltd. ${ }^{12}$

\section{Retained Placenta with Placenta Accreta SPECTRUM}

Regarding the first case, ${ }^{12}$ high-resolution SMI with an 18-MHz linear probe clearly revealed irregular minimal invasion by the retained placenta into the anterior myometrium, as well as disruption of decidual vessels at this pathological lesion with the retained placenta showing abnormal blood flow (Fig. 27).

In the second case, ${ }^{12}$ abundant blood flow was identified by conventional SMI in the placental bed next to the uterine wall (Figs 28 and 29). High-resolution SMI in conjunction with an $18-\mathrm{MHz}$ probe clearly revealed myometrial loss anterior to fundal lesions (Fig. 30), and abnormally dilated, torturous, vessels
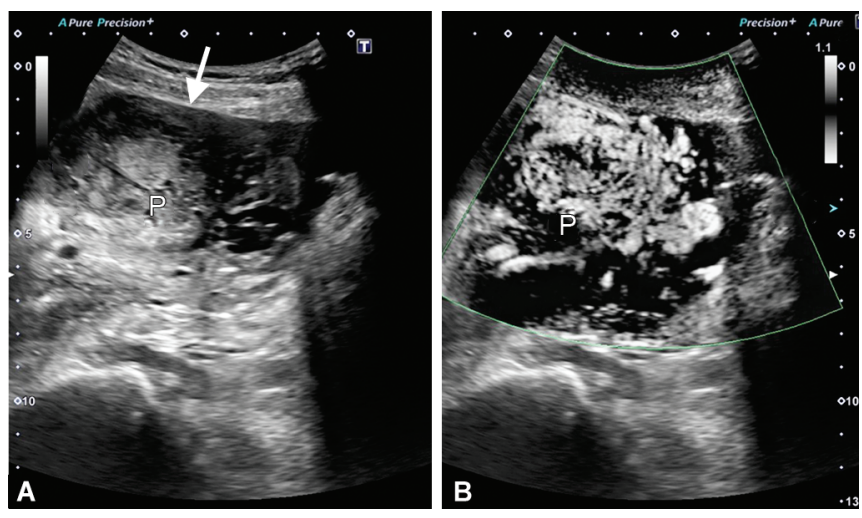

Figs 29A and B: Retained placenta with placenta accreta spectrum. (A) Two-dimensional sonography shows broad anechoic lesions in the uterus (arrow); (B) Conventional monochrome superb microvascular imaging (SMI) reveals abundant blood flow in the placental bed adjacent to the uterine wall. P, placenta

invading up to the uterine serosa (snow storm-like appearance) (Fig. 31).

\section{Conclusion}

It is possible for SMI with an 18-MHz probe to clearly depict lowvelocity blood flow in normal and abnormal placentas. However, $\mathrm{SMI}$ with an 18-MHz probe is markedly limited by shallow probe penetration. ${ }^{14}$ Thus, the probe's sole use is for an anterior implanted placenta. Motion artifacts and noise resulting from fetal movements are also limitations, along with maternal respiratory movements and obesity. However, in both clinical practice and research, this modality may provide new knowledge regarding the pathophysiology of normal and abnormal placental microvasculatures. 


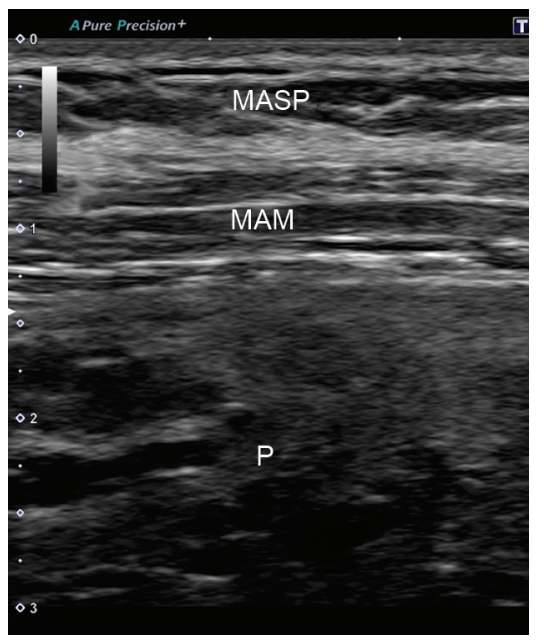

Fig. 30: Retained placenta with placenta accreta spectrum. Highresolution ultrasound with an $18-\mathrm{MHz}$ probe clearly demonstrates the loss of myometrium anterior to fundal lesions and depicts abnormally dilated torturous echo-free spaces. MAM, maternal abdominal muscle; MASF, maternal abdominal subcutaneous fat, P, placenta. Courtesy: Reprinted with permission from Jaypee Brothers Medical Publishers (P) Ltd. $^{12}$

\section{References}

1. Hasegawa J, Suzuki N. SMI for imaging of placental infarction. Placenta 2016;47:96-98. DOI: 10.1016/j.placenta.2016.08.092.

2. Hata T, Mori N, AboEllail MAM, et al. SMI with Doppler luminance in obstetrics. Donald School J Ultrasound Obstet Gynecol 2019;13(2):6977. DOI: 10.5005/jp-journals-10009-1588.

3. Hasegawa J, Yamada H, Kawasaki E, et al. Application of superb micro-vascular imaging (SMI) in obstetrics. J Matern Fetal Neonatal Med 2018;31(2):261-263. DOI: 10.1080/14767058.2016. 1278206.

4. Hata T, Kanenishi K, Yamamoto K, et al. Microvascular imaging of thick placenta with fetal growth restriction. Ultrasound Obstet Gynecol 2018;51(6):837-839. DOI: 10.1002/uog.18837.

5. Mack LM, Mastrobattista JM, Gandhi R, et al. Characterization of placental microvasculature using superb microvascular imaging. J Ultrasound Med 2019;38(9):2485-2491. DOI: 10.1002/jum. 14919.

6. Furuya N, Hasegawa J, Homma C, et al. Novel ultrasound assessment of placental pathological function using superb microvascular imaging. J Matern Fetal Neonatal Med 2020. 1-4. DOI: 10.1080/14767058.2020.1795120.

7. Sainz JA, Carrera J, Borrero C, et al. Study of the development of placental microvascularity by Doppler SMI (superb microvascular imaging): a reality today. Ultrasound Med Biol 2020;46(12):3257-3267. DOI: 10.1016/j.ultrasmedbio.2020.08.017.
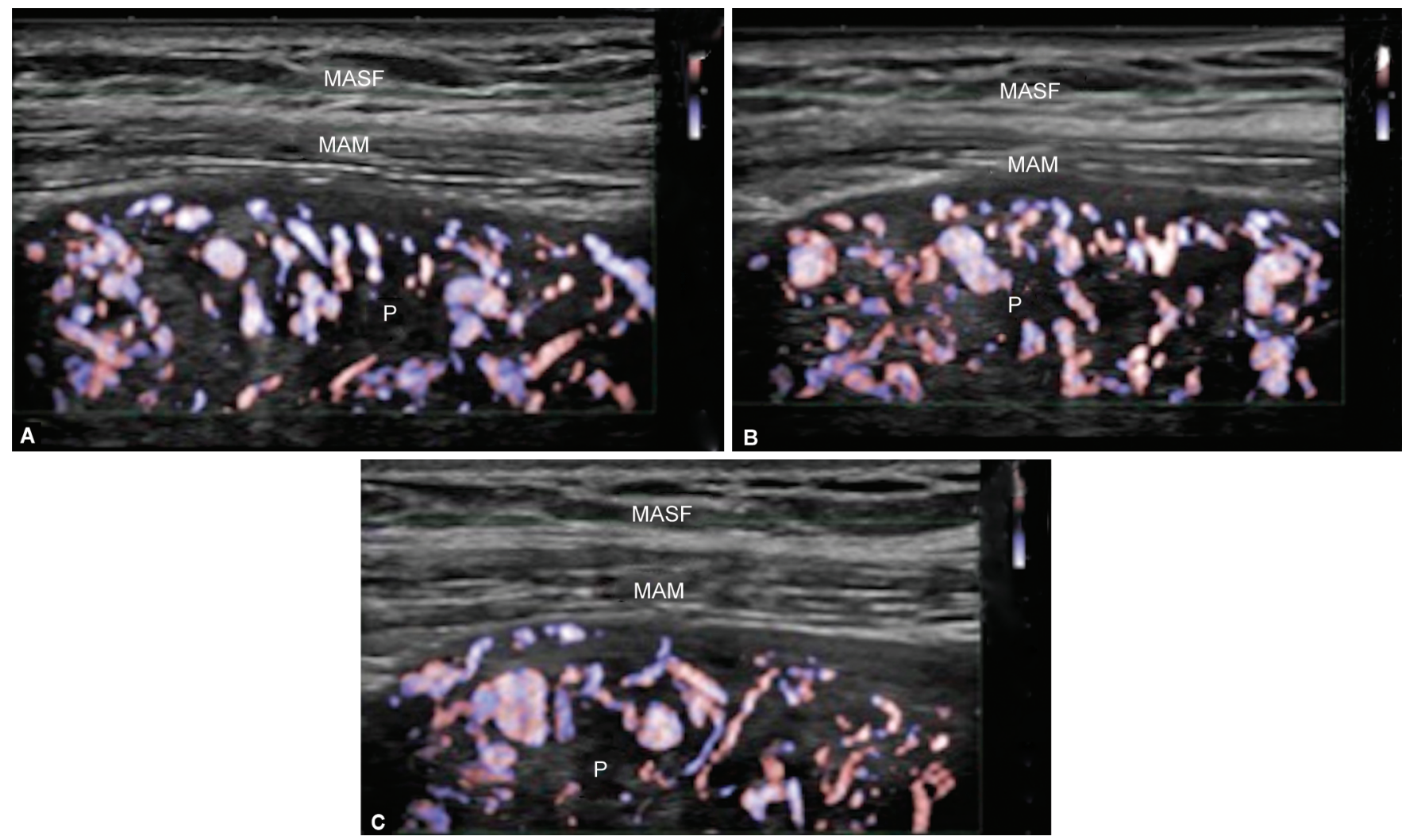

Figs $31 \mathrm{~A}$ to C: Retained placenta with placenta accreta spectrum. Superb microvascular imaging (SMI) with an 18-MHz probe clearly demonstrates the loss of myometrium anterior to fundal lesions. Abnormally torturous, abundant blood flow (snow storm-like appearance) invading until the uterine serosa is evident ( $A$ and $B$ ). Abnormally dilated vessels are also evident (C). MAM, maternal abdominal muscle; MASF, maternal abdominal subcutaneous fat; $P$, placenta 
8. Inoue A, Horinouchi T, Yoshizato T, et al. Peculiar blood flow profiles among placental chorionic villous vessels of an abnormally thick placenta in a case of systemic lupus erythematosus characterized using microvascular imaging. J Obstet Gynaecol Res 2020(12). DOI: 10.1111/jog.14502.

9. Sun L, Li N, Jia L, et al. Comparison of superb microvascular imaging and conventional Doppler imaging techniques for evaluating placental microcirculation: a prospective study. Med Sci Monit 2020;10:e926215. DOI: 10.12659/MSM.926215.

10. Horinouchi T, Yoshizato T, Kojiro-Sanada S, et al. Missing decidual Doppler signals as a new diagnostic criterion for placenta accreta spectrum: a case described using superb microvascular imaging. J Obstet Gynaecol Res 2020(1). DOI: 10.1111/jog. 14441.
11. Hata T, Mori N, AboEllail MAM, et al. Advances in color Doppler in obstetrics. J South Asian Feder Obst Gynae 2019;11(1):1-12. DOI: 10.5005/jp-journals-10006-1641.

12. Hata $T$, Hanaoka $U$, Mori $A$, et al. Superb microvascular imaging of retained placenta with placenta accreta spectrum. Donald School J Ultrasound Obstet Gynecol 2019;13(3):85-87. DOI: 10.5005/ jp-journals-10009-1600.

13. Hasegawa J, Kurasaki A, Hata T, et al. Sono-histological findings of the placenta accreta spectrum. Ultrasound Obstet Gynecol 2019;54(5):705-707. DOI: 10.1002/uog.20207.

14. Hata T, Koyanagi A, Yamanishi T, et al. Superb microvascular imaging with Doppler luminance using $18-\mathrm{MHz}$ probe to visualize fetal intraabdominal blood vessels and organ microvasculature. J Perinat Med 2020;48(2):184-188. DOI: 10.1515/jpm-2019-0411. 